\title{
Development of Nickel Doped Zinc Ferrite Nanocomposites as Magnetically Recoverable Catalytic Material for The Synthesis of Biphenyl Methane
}

\author{
Divya S. Nair, Dileep P S
}

Department of Chemistry, St. Teresa's College, Ernakulam-682011, India

\begin{abstract}
Magnetically active nickel doped zinc ferrite nanoparticles with chemical composition $\mathrm{Nix}_{\mathrm{Xn}} \mathrm{Zn}_{1-\mathrm{x}} \mathrm{Fe}_{2} \mathrm{O}_{4}(\mathrm{x}-0.0$, $0.25,0.5,0.75$ and 1.0) were successfully synthesized by sol-gel auto-combustion method using high purity metal nitrates and ethylene glycol as gelling agent. The prepared samples were characterized by X-ray Diffraction (XRD), Transmission Electron Microscopy (TEM), X-ray Fluorescence (XRF) and Fourier Transform Infra-Red spectral (FTIR) analyses. TEM images and particle size distribution profile reveals the agglomeration tendency during nickel doping suggest the magnetic nature of particles. The remarkable change in the magnetic behaviour of nickel doped zinc ferrite samples provide an easy recovery and regeneration of the material and thus making an excellent candidate for benzylation reaction without any remarkable fall in the catalytic performance for repeated cycles.
\end{abstract}

Keywords : Nanocomposites, Spinels, Catalysis, Benzylation, TEM

\section{INTRODUCTION}

Spinel structured nano ferrite composites are still in the spotlight of current nanoscience and technology due to their immense application potential. Very interesting aspects of these materials are their excellent magnetic properties accompanied with modifiable functional properties during doping and these can also be fine tuned by particle size and shape up to some extent [1-2]. Ferrites with spinel structure have the general chemical formula $\mathrm{M}^{2+} \mathrm{Fe}_{2}{ }^{3+} \mathrm{O}_{4}$, is based on cubic close packing of oxide ions, forming tetrahedral and octahedral coordination sites and are occupied either by divalent or trivalent metal ions [34]. The properties of spinel ferrites depend mainly on the redox properties of metal ions and their distribution among octahedral and tetrahedral coordination sites. The surface of spinel structure mostly contains octahedral sites and consequently all the physical and chemical properties are hugely related to octahedral cations [5]. The properties of ferrites are also highly sensitive to various factors such as mode of preparation, preparative conditions and nature of dopants. Any variation in these parameters can lead to modification in the properties of ferrites [2].

Spinel ferrite nanocomposites are suggested as multifunctional materials for exploitation in biomedicine, magnetic recording, catalysis including magnetically separable catalysts, sensing etc [6-7]. Transition metal doped spinel nanoferrite composites have been used as recoverable and reusable catalytic material for chemical engineering applications. By modifying the composition of spinel ferrite while maintaining the basic crystalline structure intact, these stand out among other stoichiometric compounds. The bonding in most ferrites has an ionic character since cations are surrounded by oxide ions and conversely anions have cations as nearest 
neighbours. Magnetic ordering in ferrites mainly depends on the ionic interactions between octahedral and tetrahedral metal cations and anions in the spinel lattice. However, in most cases a resulting magnetic moment remains due to the fact that magnetic lattices contain different numbers of cations especially the octahedral cations [8]. In the case of spinels, the magnetic structure can be inferred from through exchange interactions occur between tetrahedral and octahedral cations. Tuning of magnetic properties of spinel ferrites via site distribution in spinel lattice is an upstanding approach so that the site occupation must be carefully evaluated and controlled according to applications. Among different popular synthetic procedures for spinel ferrites, sol-gel process was found successful route which allows rather good control over homogeneity of doped samples with good particle size distribution.

In the present work, we emphasize on the understanding of morphological characterization of nickel doped zinc ferrite nanocomposites and their use as a magnetically recoverable and active catalyst for the synthesis of biphenyl methane via benzylation of benzene under moderate reaction conditions. Friedel-Crafts (F C) alkylation reaction has been selected for the elucidation of easy recovery and regeneration of nickel doped zinc ferrite nanocomposites by magnetic means. The lack of easy recovery and regeneration is the main problem associated with many of the heterogeneous catalytic materials used for different reactions especially in organic synthesis. The development of suitable materials with excellent reusability characteristics has not been achieved so far and is still a difficult task too. In this aspect magnetically active materials having excellent catalytic activity definitely contribute new pathways in the field of heterogeneous catalysis.

\section{METHODS AND MATERIAL}

\section{Preparation and characterisation of magnetic nanocatalysts}

Different compositions of $\mathrm{Nix}_{\mathrm{Xn}} \mathrm{n}_{1-\mathrm{x}} \mathrm{Fe}_{2} \mathrm{O}_{4}(\mathrm{x}-0.0,0.25$, $0.50,0.75,1.0)$ were prepared by sol-gel auto combustion method. Required stoichiometric ratio of $\mathrm{Fe}\left(\mathrm{NO}_{3}\right)_{3} .9 \mathrm{H}_{2} \mathrm{O}, \mathrm{Ni}\left(\mathrm{NO}_{3}\right)_{2} .6 \mathrm{H}_{2} \mathrm{O}, \mathrm{Zn}\left(\mathrm{NO}_{3}\right)_{2} .6 \mathrm{H}_{2} \mathrm{O}$ were dissolved in minimum amount of ethylene glycol (all are from Merck Chemicals, Mumbai, India) at room temperature and heated at $60^{\circ} \mathrm{C}$ to get a wet gel. This gel dried at $120^{\circ} \mathrm{C}$ self-ignited to form a fluffy product which was calcined at $700^{\circ} \mathrm{C}$ for $4 \mathrm{~h}$ to achieve transformation into spinel phase. The synthesized nanocomposites were characterized by different physicochemical tools such as X-ray Diffraction (XRD), Transmission Electron Microscopy (TEM), Xray Fluorescence (XRF) and Fourier Transform InfraRed spectral (FTIR) analysis. The synthesis and characterization of the catalyst composites are detailed in our previous publications [9-10]. The effect of nickel substitution on the structural and morphological properties of zinc ferrite nanocomposites was analyzed with respect to distribution of particles diameter with the help of TEM histogram.

\section{Application of magnetic nanocatalysts for $\mathrm{F} \mathrm{C}$ benzylation and its recovery}

Benzylation of benzene (Merck, India) with benzyl chloride (LobaChemie, India) in the required stoichiometry was investigated under optimized reaction conditions. The reaction was carried out in a two-necked RB flask fitted with a water condenser and a magnetic stirrer equipped with a thermocouple. Specific amount of prepared catalyst was added to the reaction mixture and then magnetically stirred continuously. Samples were withdrawn at 10 minutes regular intervals of time up to two hours, filtered and 
the progress of the reaction measured using Perkin Elmer Clarus 580 Model GC.

The recovery and reusability of the magnetic nanocomposites were examined by retaining the catalyst by filtration from the reaction mixture via magnetic means. The recovered catalyst was washed with distilled water and then by acetone to remove residual salts and organics and dried in an air oven at $120^{\circ} \mathrm{C}$ and used for five repeated reaction cycles. Leaching studies of the catalyst using PerkinElmer Analyst 700 Atomic Absorption Spectrophotometer substantiate the chemical and structural stability of the material during repeated usages.

\section{RESULTS AND DISCUSSION}

$\mathrm{XRD}$ studies confirmed the spinel structure of $\mathrm{Zn}_{\mathrm{N}} \mathrm{Ni}_{1}$ ${ }_{x} \mathrm{Fe}_{2} \mathrm{O}_{4}(\mathrm{x}-0.0,0.25,0.50,0.75,1.0)$ nanocomposites with good crystallinity and the average crystallite size estimated from the Scherrer equation was found in the range 14.4-39.6 nm. FTIR spectra again confirmed the spinel structure by revealing two absorption bands in the range $400-450 \mathrm{~cm}^{-1}$ and $550-600 \mathrm{~cm}^{-1}$ respectively due to the vibrations of oxide ions with the divalent and trivalent metal ions in octahedral and tetrahedral sites in the spinel lattice. Stoichiometry of different ferrite catalysts were verified by XRF studies and the obtained results are in good agreement with the theoretical values.

Transmission Electron Micrographs of different compositions of $\mathrm{Ni}-\mathrm{Zn}$ nanoferrites along with particle size distribution is given in Fig. 1. TEM images yields the particle size in the range $15-39 \mathrm{~nm}$ which nearly complements with the XRD results. It also gives information on aggregation and other morphological changes during successive doping process. The images suggest considerable degree of agglomeration of ferrite particles due to its magnetic nature and also by the union of primary particles held together by weak surface interaction such as Vander Waals forces. The agglomeration tendency of nanoparticles can be explained by its structure and surface area to volume ratio. Substitution of nickel into normal spinel structured zinc ferrite changes to inverse spinel structure with $\mathrm{Ni}^{2+}$ ions in the octahedral sites which are more peripheral and they experience a permanent magnetic moment proportional to their volume. Hence the particles get agglomerated more rapidly and as a result their particle size increases with nickel substitution [11-12]. The degree of agglomeration tendency zinc ferrite nanocomposites increase with nickel doping.
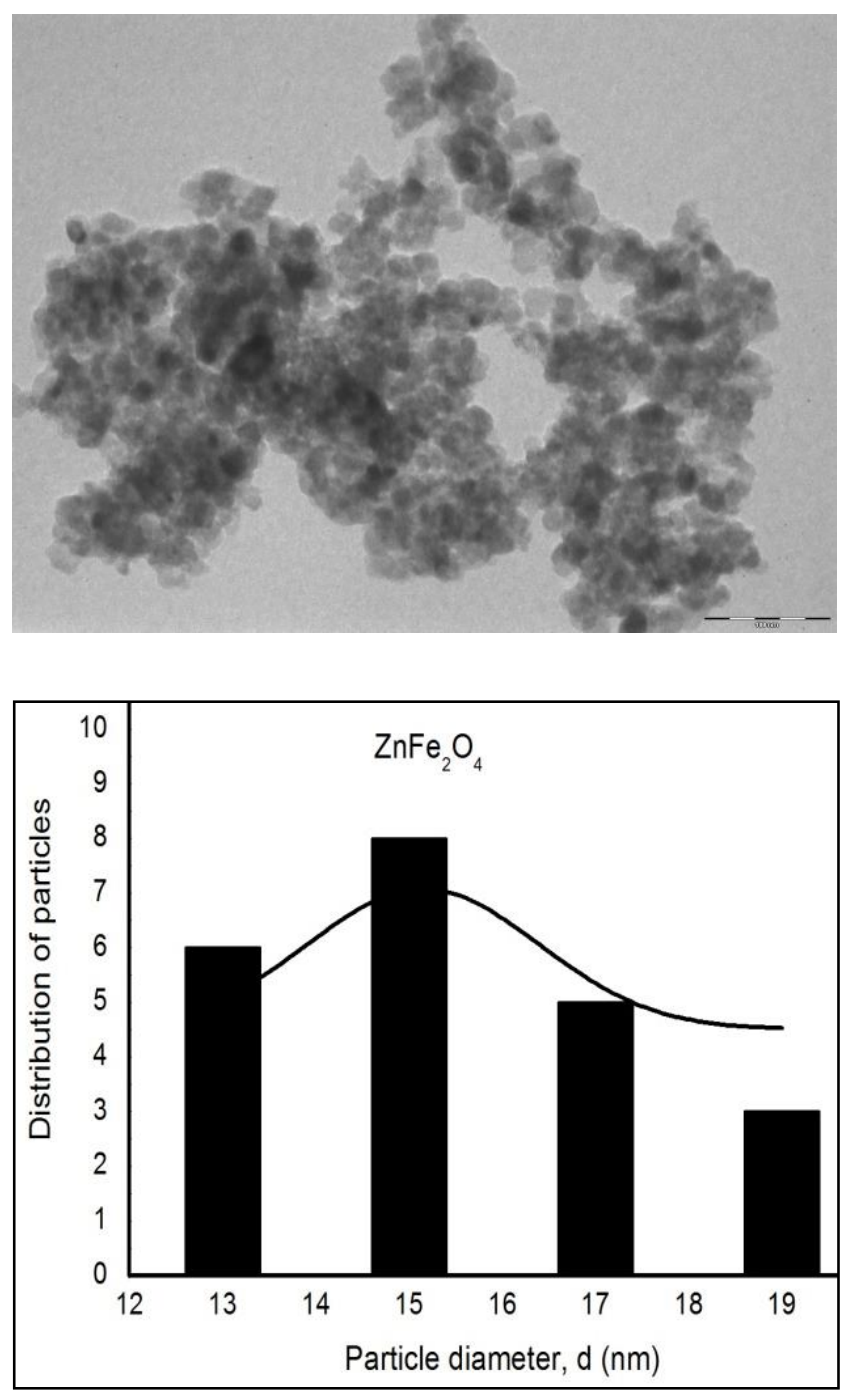

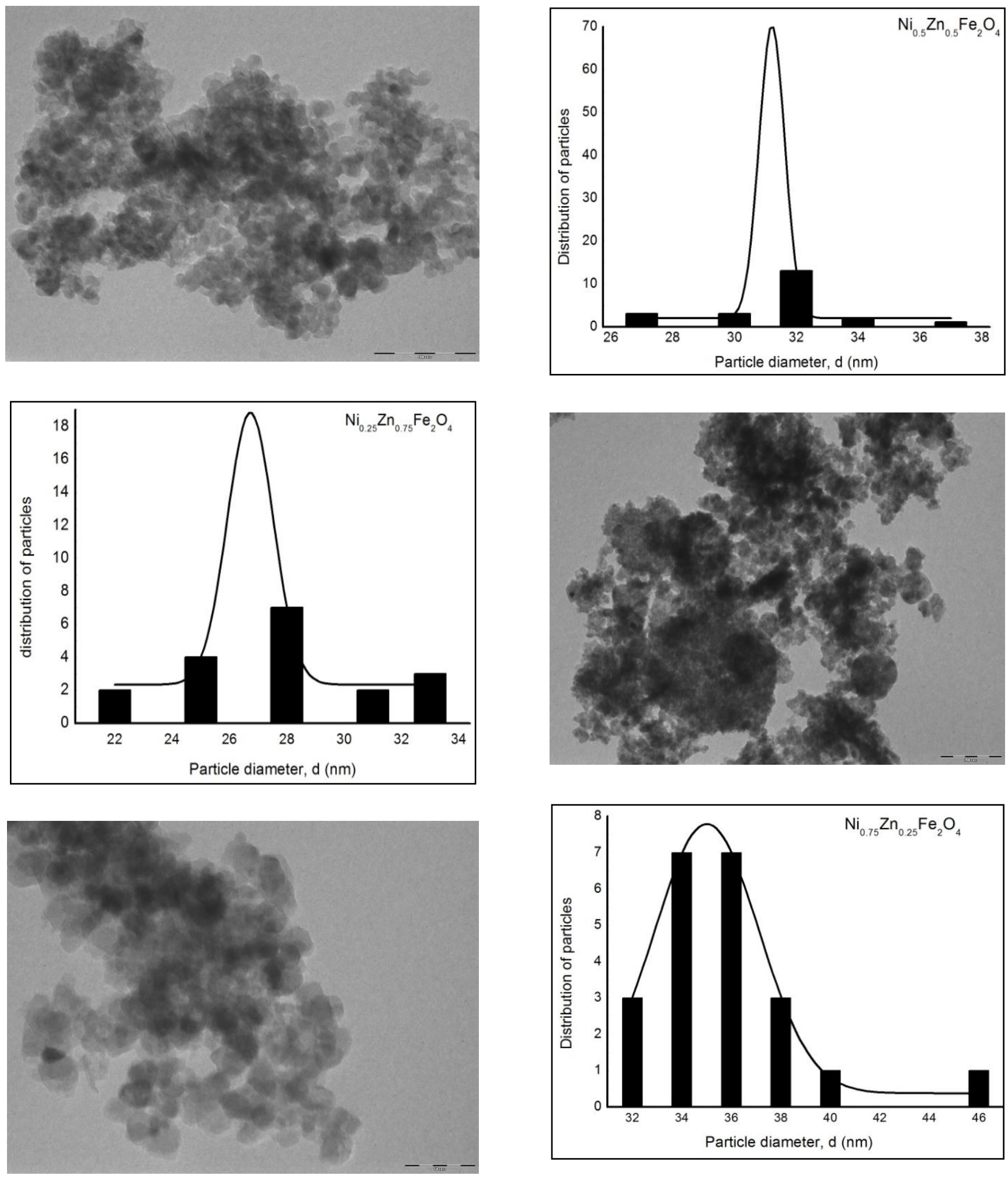

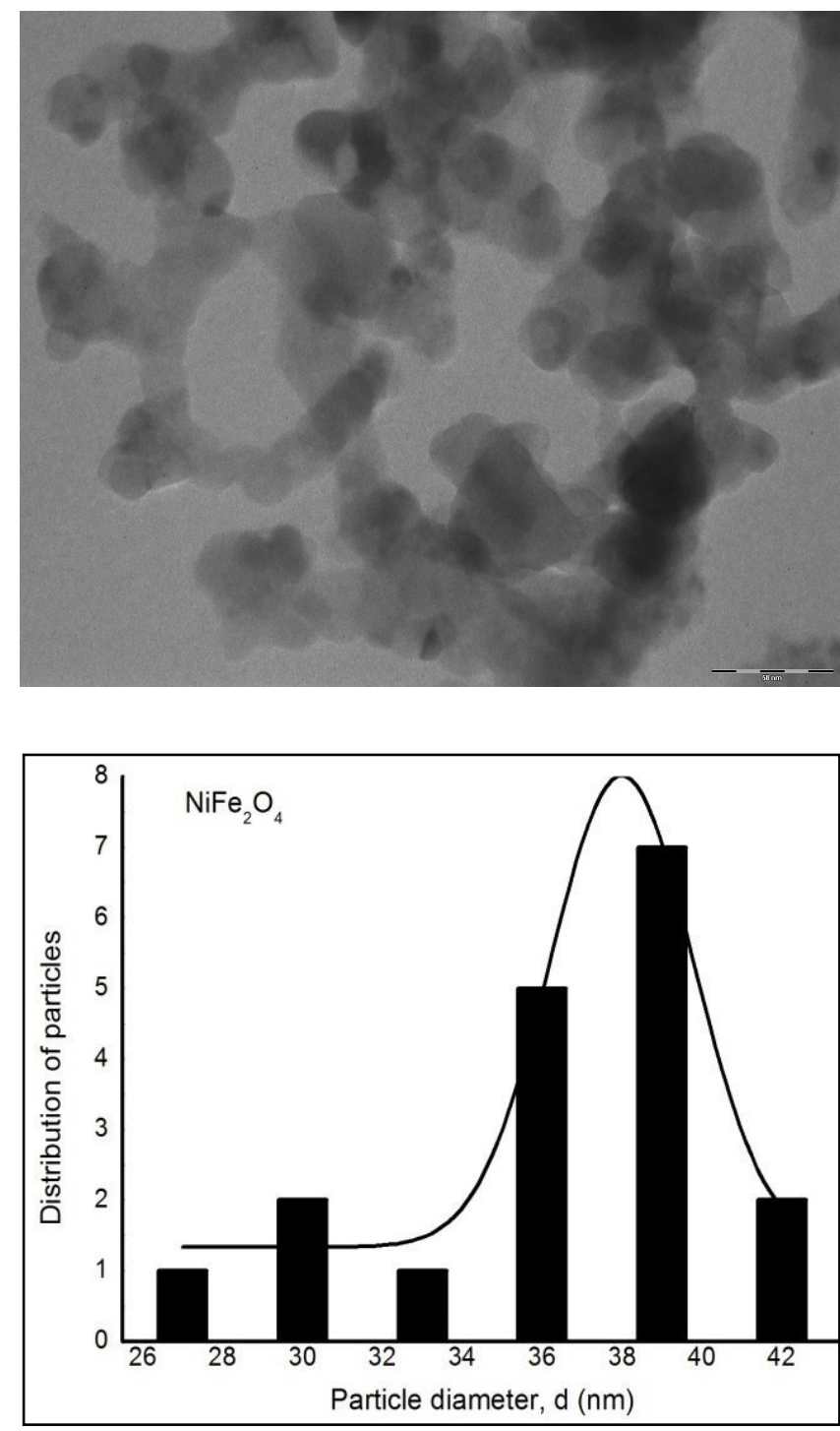

Fig. 1. TEM images of $\mathrm{Nix}_{\mathrm{Z}} \mathrm{Zn}_{1-\mathrm{x}} \mathrm{Fe}_{2} \mathrm{O}_{4}(\mathrm{x}-0.0,0.25,0.50$, $0.75,1.0)$, with distribution of particle diameters

Magnetic materials as recoverable catalysts for benzylation of benzylation
The magnetic property of nickel doped zinc nanocomposites was elucidated by its recovery during benzylation of benzene. The rate of the reaction via conversion of one of the reactant, benzyl chloride to the desired product during reaction was studied over 110 minutes and the results are shown in Table 1. A continuous increase in rate of conversion of benzyl chloride with time was observed with all compositions of nickel and zinc with $100 \%$ selectivity to biphenyl methane. An induction period was noticed for zinc ferrite nanocomposites with $9.5 \%$ of benzyl chloride conversion which then increased gradually to $52 \%$ in one hour. The substitution of nickel into zinc ferrite shows an increase in catalytic activity initially. The percentage conversion of benzyl chloride reaches its maximum at lower nickel doping. Further increase in nickel content beyond $\mathrm{x}-0.25$, decreases the catalytic performance of zinc ferrite nanocomposites. The un-substituted nickel ferrite shows the least catalytic activity. The decrease in catalytic performance during nickel doping into zinc ferrite matrix is attributed to particle agglomeration due to the magnetic behaviour of ferrite nanoparticles. In addition to this, because of excellent magnetic behaviour the separation of nanocomposite catalyst from the reaction mixture was easy for another five repeated cycles. It is clear from Table 2 that the activity of the magnetic material for benzylation reaction is almost the same.

Table 1. Catalytic performance of nickel doped zinc ferrite nanocomposites for benzylation of benzene.

\begin{tabular}{|c|c|c|c|c|c|}
\hline \multirow{2}{*}{$\begin{array}{c}\text { Time } \\
(\mathrm{min})\end{array}$} & \multicolumn{5}{|c|}{ \% of conversion of benzyl chloride } \\
\cline { 2 - 6 } & $\mathrm{ZnFe}_{2} \mathrm{O}_{4}$ & $\mathrm{Ni}_{0.25} \mathrm{Zn}_{0.75} \mathrm{Fe}_{2} \mathrm{O}_{4}$ & $\mathrm{Ni}_{0.5} \mathrm{Zn}_{0.5} \mathrm{Fe}_{2} \mathrm{O}_{4}$ & $\mathrm{Ni}_{0.75} \mathrm{Zn}_{0.25} \mathrm{Fe}_{2} \mathrm{O}_{4}$ & $\mathrm{NiFe}_{2} \mathrm{O}_{4}$ \\
\hline 0 & 0 & 0 & 0 & 0 & 0 \\
\hline 10 & 9.5 & 26.9 & 11.2 & 12.8 & 8.4 \\
\hline 20 & 15.0 & 31.8 & 17.8 & 20.6 & 21.9 \\
\hline 40 & 29.7 & 76.4 & 34.1 & 42.0 & 31.8 \\
\hline 60 & 51.6 & 98.7 & 54.7 & 52.3 & 41.7 \\
\hline
\end{tabular}




\begin{tabular}{|c|c|c|c|c|c|}
\hline 80 & 84.3 & 100 & 63.4 & 54.5 & 47.6 \\
\hline 100 & 100 & 100 & 73.5 & 59.1 & 52.8 \\
\hline 120 & 100 & 100 & 81.7 & 67.9 & 57.3 \\
\hline
\end{tabular}

Table 2. Recycling studies of nickel-zinc ferrite nanocatalyst

\begin{tabular}{|c|c|}
\hline $\begin{array}{c}\text { No. of catalytic } \\
\text { cycles }\end{array}$ & $\begin{array}{c}\text { \% of conversion of } \\
\text { benzyl chloride }\end{array}$ \\
\hline 1 & 100 \\
\hline 2 & 99.0 \\
\hline 3 & 97.3 \\
\hline 4 & 92.9 \\
\hline 5 & 91.8 \\
\hline
\end{tabular}

\section{IV.CONCLUSION}

High purity nickel doped zinc ferrite nanocomposites with chemical composition $\mathrm{Ni}_{x} \mathrm{Zn}_{1-x} \mathrm{Fe}_{2} \mathrm{O}_{4}$ ( $\mathrm{x}-0.0,0.25$, $0.5,0.75$ and 1.0 ) were synthesized by sol-gel autocombustion method. The remarkable change in the magnetic behaviour of nickel doped zinc ferrite nanocomposites were revealed from TEM images. These magnetically active materials were found excellent as a recoverable and regenerative catalyst for benzylation reaction by magnetic way of separation.

\section{ACKNOWLEDGEMENT}

Senior Research Fellowship to Divya S. Nair from University Grants Commission, New Delhi, India is gratefully acknowledged.

\section{REFERENCES}

[1]. S. Monica, R. Peelamedu, R. Roy, P. Yadoji, J. Magn. Magn. Mater. 279 (2004) 195.

[2]. H. W. Wang, S. C. Kung, J. Magn. Magn. Mater. 270 (2004) 230.
[3]. J.N. Park, J. KukShon, M. Jin, S.H. Hwang, G.O. Park, J.H. Boo, T.H. Han, J.M. Kim, Chem. Lett. 39 (2010) 493-498.

[4]. J.C. Lou, C.K. Chang, Environ. Eng. Sci. 23 (2006) 1024-1031.

[5]. C.G. Ramankutty, S. Sugunan; Appl. Catal. A: Gen. 218 (2001) 39-51.

[6]. K. Kamala Bharathi, R. S. Vemuri, M. Noor-AAlam, C. V. Ramana, Thin Solid Films 520 (2012) 1794.

[7]. L. M. Salah, A. M. Moustafa, I. S. Ahmed Farag, Ceramic Intern. 38 (2012) 5605.

[8]. N. Rezlescu, E. Rezlescu, P. D. Pop, C. Doroftei, M. Ignat, Romanian Reports in Phys. 65 (2013) 1348-1356.

[9]. M. Kurian, D.S. Nair, J. Water Process Eng. 8 (2015) 37-49.

[10]. D.S. Nair, M. Kurian, J. Water Process Eng. 16 (2017) 69-80.

[11]. B. Issa, I. M. Obaidat, B. A. Albiss and Y. Haik, Int. J. Mol. Sci. 14 (2013) 21266.

[12]. D. A. Usanov, A. E. Postel'ga, T. S. Bochkova and V. N. Gavrilin, Techn. Phy. 61 (2016) 464.

\section{Cite this article as :}

Divya S. Nair, Dileep P S, "Development of Nickel Doped Zinc Ferrite Nanocomposites as Magnetically Recoverable Catalytic Material for The Synthesis of Biphenyl Methane", International Journal of Scientific Research in Science and Technology (IJSRST), Online ISSN : 2395-602X, Print ISSN : 23956011, Volume 6 Issue 6, pp. 65-70, NovemberDecember 2019. Available at doi : https://doi.org/10.32628/IJSRST19666 Journal URL : http://ijsrst.com/IJSRST19666 